\title{
Pelatihan Kegawatan Kardiovaskuler Bagi Perawat
}

\author{
Nurhasan Agung Prabowo ${ }^{1,2 *}$, Risalina Myrtha, ${ }^{1,2}$, Hendrastutik Apriningsih ${ }^{1,2}$, \\ Tonang Dwi Ardyanto ${ }^{1,2}$, Astri Tantri Indriani ${ }^{1,2}$, Frieska Dyanneza ${ }^{1,2}$, Niken Dyah \\ Aryani Kuncorowati ${ }^{1,2}$, Andri Haryanto ${ }^{1,2}$, Muchtar Hanafi ${ }^{1,2}$, Yeni Farida ${ }^{2}$, Laily \\ Shofiyah ${ }^{1,2}$
}

1. Fakultas Kedokteran Universitas Sebelas Maret

2. Rumah Sakit Universitas Sebelas Maret

\begin{abstract}
ABSTRAK
Pendahuluan: Keadaan darurat bisa terjadi pada siapa saja, di mana saja, kapan saja. Dalam situasi ini, tenaga medis harus siap untuk bertindak sesuai dengan tugas dan tanggung jawab mereka. Perawat adalah profesional medis yang bertanggung jawab untuk perawatan pasien darurat. Sebuah survei tahun 2019 di lapangan menemukan bahwa sebagian besar perawat tidak memahami keadaan darurat kardiovaskular. Ketua tim PPNI (Perhimpunan Perawat Nasional Indonesia) RS UNS menyatakan bahwa beberapa masalah terbesar yang dihadapi PPNI adalah pengetahua perawat tentang pembacaan EKG yang terbatas, perawat tidak mengetahui kondisi kegawatan jantung dan pelatihan pertolongan pertama kegawatan jantung jarang ditemui. Selain itu tidak ada pedoman khusus kegawatan kardiovaskuler pada perawat. Tujuan pengabdian ini adalah meningkatkan pengetahuan kegawatan kardiovaskuler pada perawat PPNI RS UNS.

Metode: Kegiatan pengabdian masyarakat yang dilakukan meliputi pelatihan secara daring pada hari Kamis 16 April 202 di RS UNS, selain itu juga pembuatan buku Panduan membaca EKG dan leaflet cara membaca EKG bagi perawat.

Hasil: Terjadi peningkatan pengetahuan perawat terhadap EKG dengan peningkatan nilai pretes 55,5 menjadi 72,5 dengan skala 100 (peningkatan 17\%). Uji t berpasangan menunjukkan adanya perbedaan signifikan terkait pengetahuan perawat sebelum dan setelah pelatihan $(\mathrm{p}=0,001)$.

Kesimpulan: Pelatihan kegawatan kardiovaskuler pada perawat meningkatkan pengetahuan perawat mengenai kegawatan kardiovaskuler
\end{abstract}

Kata Kunci: Pelatihan; Kegawatan Kardiovaskuler; Perawat; PPNI RS UNS.

\begin{abstract}
Introduction: An emergency can happen to anyone, anywhere, anytime. In this situation, medical personnel must be prepared to act following their duties and responsibilities. Nurses are medical professionals responsible for the care of emergency patients. A 2019 survey in the field found that most nurses did not understand cardiovascular emergencies. The head of the PPNI (Indonesian National Nurses Association) team at UNS Hospital suggested there were several problem faced by PPNI such as the nurses' knowledge to read ECG was limited, nurses did not know about the emergency in cardiology and the training for the first aid in cardiac emergencies was rare. In addition, there are no specific guidelines for cardiovascular emergencies in nurses. The purpose of this community empowerment is to increase knowledge of cardiovascular emergencies in PPNI nurses at UNS Hospital.

Methods: This community empowerment activities carried out included online training on Thursday, April 16, 202, at UNS Hospital, in addition to making an ECG reading guidebook and a leaflet on how to read an ECG for nurses.

Results: There was an increasing in the nurses' knowledge to read ECG which was documented from the mean of pretest score (55.5) compare to posttest score (72.5) (an increase of 17\%). Paired t-test showed $a$ significant difference in nurses' knowledge before and after training $(\mathrm{p}=0.001)$.

Conclusion: Cardiovascular emergency training for nurses increases nurses' knowledge about cardiovascular emergencies.
\end{abstract}

Keywords: Training, Cardiovascular Emergency, Nurse, PPNI UNS Hospital.

Correspondence: Nurhasan Agung Prabowo, dr.Sp.PD, M.Kes, Fakultas Kedokteran Universitas Sebelas Maret, dr.nurhasan21@staff.uns.ac.id 


\section{PENDAHULUAN}

Penyakit jantung adalah penyebab utama kematian di seluruh dunia, mencapai sekitar 17,7 juta kematian secara global, atau $31 \%$ dari semua kematian di seluruh dunia ${ }^{1}$. Aritmia adalah kelainan elektrofisiologis jantung yang disebabkan oleh gangguan nadi, atau gangguan konduksi jantung. Kematian akibat aritmia mendadak diperkirakan mencapai 50\% dari seluruh kematian yang diakibatkan oleh penyakit jantung ${ }^{2}$.

Pada pasien dengan kelainan irama jantung (aritmia), pemeriksaan rutin dengan elektrokardiogram (EKG) didapatkan mencapai $12 \%$ pasien. Aritmia yang tergolong kegawatan jika terjadi takikardia ventrikel dan fibrilasi ventrikel. Kondisi tersebut menyebabkan 300.000 kematian per tahun di Amerika Serikat ${ }^{2}$. Insiden aritmia meningkat seiring bertambahnya usia. Sejalan dengan hal tersebut, prevalensi aritmia di Indonesia meningkat seiring bertambahnya usia, mencapai $70 \%$ pada pasien usia $65-85$ tahun dan $8 \%$ pada orang di atas 85 tahun $^{3}$. Perawat terlebih dahulu harus mampu menginterpretasikan hasil rekaman elektrokardiogram (EKG), meliputi gangguan konduksi, aritmia, dan gangguan miokard karena perawat adalah orang yang selalu ada di samping pasien ${ }^{2,4}$.

Misi PPNI adalah mengutamakan kepentingan anggotanya dalam menjalankan praktik profesional, etis, dan bermanfaat sebagai suatu profesi. Salah satu peran PPNI adalah meningkatkan pengetahuan anggota keperawatan PPNI. Selama pandemi COVID-19 ini, pelatihan kegawatan kardiovaskuler untuk perawat menjadi terbatas. Masalah utama yang harus diatasi PPNI untuk mencapai misi PPNI adalah perawat memiliki pengetahuan yang terbatas tentang cara membaca EKG (Perawat kurang dapat membaca EKG karena memang tidak diajarkan secara formal dalam sistem pndidikan perawat. Namun pada prakteknya, perawat harus mengetahui jika ada kegawatan pada gambaran rekam jantung karena perawat adalah orang yang selalu bersama dengan pasien), Perawat kurang mengetahui kegawatan kardiovaskuler (Keluhan jantung pada pasien, terutama yang memiliki penyakit penyerta seperti diabetes, mungkin tidak umum. Karena itu, jika tidak ada keluhan, tenaga medis mungkin meremehkan hal tersebut, sehingga penting untuk pengenalan tanda bahaya kardiovaskuler pada perawat), dan kurangnya pelatihan mengenai kegawatan kardiovaskuler selama pandemi COVID-19.

Oleh karena itu, pelatihan mengenai kegawatan kardiovaskuler untuk perawat sangat diperlukan agar perawat dapat terus memberikan asuhan medis yang komprehensif untuk meningkatkan Kesehatan dan keselamatan. Sehingga kami mengadakan pelatihan kegawatan kardiovaskuler bagi perawat PPNI RS UNS. Tujuan pengabdian ini adalah meningkatkan pengetahuan kegawatan kardiovaskuler pada perawat PPNI RS UNS

\section{METODE}

Pada kegiatan pengabdian masyarakat ini dibagi menjadi 3 tahapan yaitu persiapan, pelaksanaan, dan pelaporan yang tampak pada gambar 1 . 


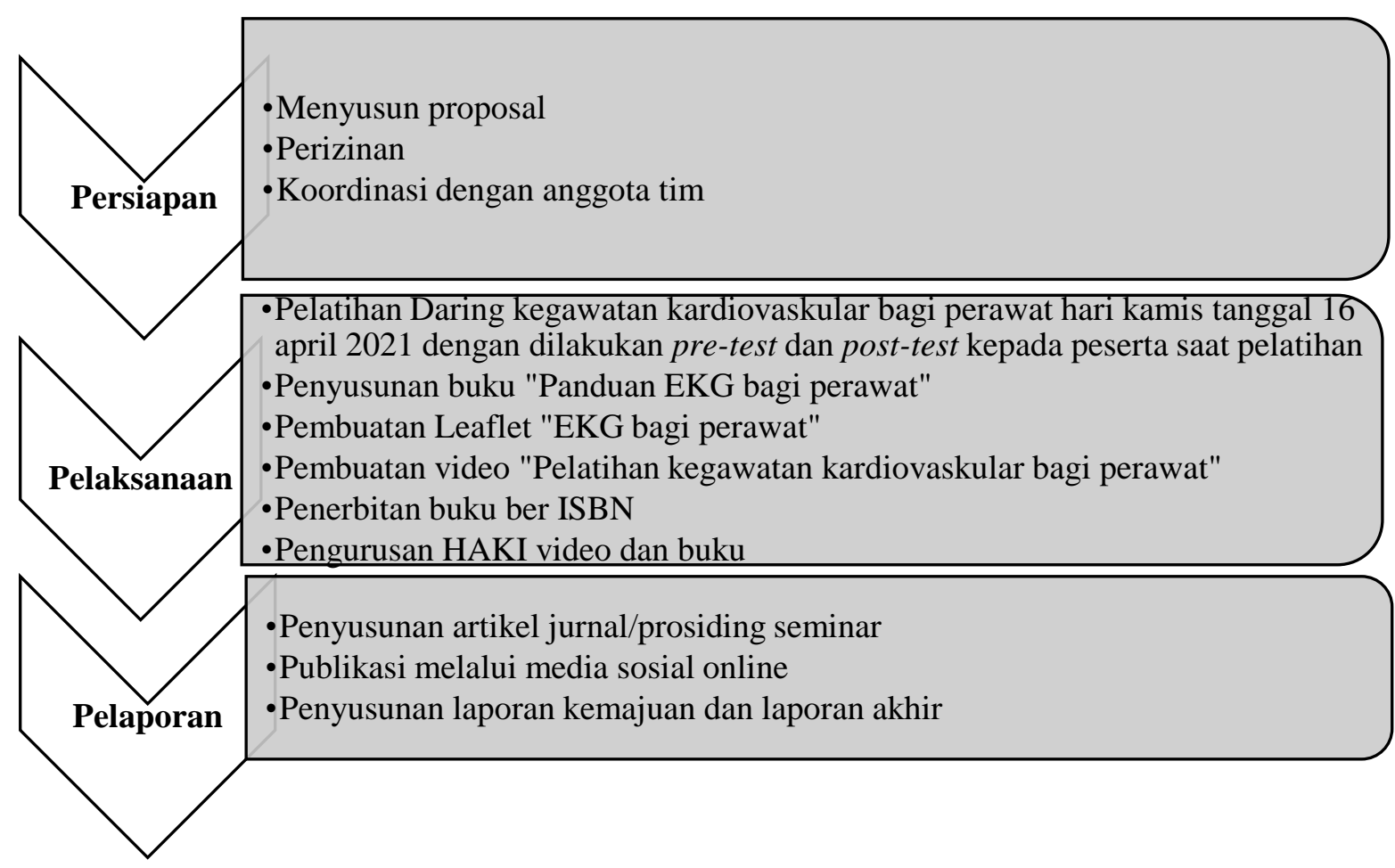

Gambar 1. Alur pelaksanaan kegiatan PKM

\section{HASIL DAN PEMBAHASAN}

Kegiatan pengabdian masyarakat yang dilakukan ini meliputi pelatihan secara daring pada hari Kamis 16 April 2021, selain itu kegiatan ini akan memberikan buku Panduan membaca EKG dan leaflet cara membaca EKG bagi perawat. Untuk menilai pengetahuan perawat sebelum dan sesudah pelatihan akan dilakukan pretest dan postest mengenai pengetahuan rekam jantung. Karena terbatasnya interaksi akibat pandemi COVID-19, pelatihan dilakukan secara online. Pengisi acara adalah dokter spesialis penyakit dalam dan jantung, yaitu dr. Nurhasan Agung Prabowo, Sp.PD, M.Kes dan dr. Risalina Myrta, Sp.JP. Pelatihan berlangsung pada hari Kamis 16 April 202 di RS UNS mulai pukul 08.00 WIB hingga selesai. Pada saat pelatihan juga dilakukan pre-test dan post-test kepada peserta. Materi ajar meliputi nyeri dada sebagai tanda kegawatan jantung dan aritmia untuk perawat. Video pelatihan berikut telah diunggah di https://www.youtube.com/watch?v=Xe3n0d44LxY.

Kegiatan lain dari pengabdian masyarakat ini adalah mmbuat buku dan leaflet "Panduan Membaca Elektrokardiogram untuk Perawat. Buku ini diharapkan sebagai panduan yang dapat digunakan oleh perawat untuk melakukan tugas pelayanan terhadap pasien. Buku ini berisi materi yang sederhana dan mudah dipahami oleh masyarakat umum. Isi buku ini menjelaskan tentang metode pemasangan elektrokardiogram, pengenalan elektrokardiogram dasar, pencitraan gelombang jantung normal, vektor arus listrik di jantung, kelainan elektrokardiografi, dan perilaku lainnya. Tindakan pertama dilakukan saat keadaan darurat elektrokardiogram pada pasien.

Pemberian pelatihan kegawatan kardiovaskular meningkatkan pengetahuan perawat dalam membaca EKG pada kondisi gawat darurat. Gambar 2 menunjukkan terdapat peningkatan kemampuan perawat dalam menginterpretasi hasil EKG yang dinilai dari adanya peningkatan rata-rata nilai pre-test dari 55,5 menjadi rata-rata nilai post test sebesar 72,5 dengan skala 100. 
Peningkatan tersebut sebersar $17 \%$. Hasil uji t-berpasangan menunjukkan adanya perbedaan signifikan terkait pengetahuan perawat sebelum dan setelah pelatihan $(\mathrm{p}=0,001)$. Hal ini secara tidak langsung akan meningkatan kualitas pelayanan terhadap pasien, sehingga tingkat kesehatan masyarakat pada umunya akan meningkat. Video pelatihan selanjutnya direncanakankan tersedia online di situs youtube untuk memperluas akses pelatihan ini dan bisa disaksikan berulang kali sehingga diharapkan menghasilkan kemanfaatan yang lebih besar.

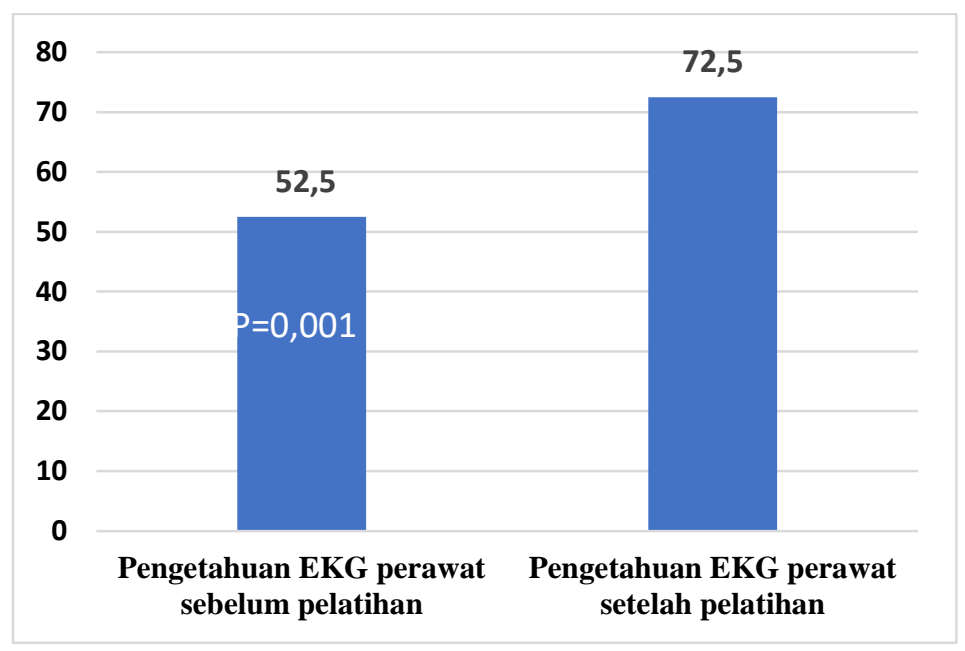

Gambar 2. Grafik nilai rerata sebelum dan sesudah pelatihan EKG bagi perawat.

Penilaian setelah pelatihan menunjukkan peningkatan pengetahuan tentang kegawatan kardiovakular di kalangan perawat. Jumlah perawat yang mengikuti kegiatan ini sebanyak 91 orang. Kemampuan mengidentifikasi kegawatan kardiovakuler pada pasien penyakit jantung membantu perawat melakukan tindakan saat pasien mengalami kondisi kegawat daruratan. Tenaga keperawatan merupakan salah satu dari sekian banyak sumber daya manusia yang bekerja di rumah sakit dan memegang peranan penting karena berhubungan dengan pasien hampir setiap waktu. Keperawatan dengan demikian menjadi sumber daya manusia di rumah sakit yang harus dikelola dengan baik ${ }^{5}$. Pemahaman kritis terutama merupakan kegiatan yang berkaitan dengan proses pengambilan keputusan dan persiapan perawat, serta perawat, untuk mengambil keputusan dalam konteks dan konteks tertentu. Untuk mencapai hal ini, perawat yang bekerja di area kritis harus memiliki pengetahuan tentang tubuh dan patofisiologi, prosedur keperawatan dan basis pengetahuan yang mampu menafsirkan dan menanggapi masalah. Perawat keperawatan kritis adalah orang yang memberikan pelayanan keperawatan langsung kepada pasien yang cedera atau sakit kritis ${ }^{6,7}$.

Keterbatasan pelaksanaan pengabdian masyarakat mengenai kegawatan kardiovaskular pada perawat adalah pelaksanaan secara daring dikarenakan kondisi pandemik yang mengurangi interaksi dengan peserta pelatihan. Saran ke depan untuk pelatihan sejenis adalah mengadakan pelatihan secara luring agar meningkatkan interaksi dengan peserta dan makin meningkatkan pemahaman peserta mengenai isi pelatihan.

\section{KESIMPULAN}

Kegiatan pengabdian masyarakat ini telah terlaksana dengan baik. Hal ini ditunjukkan dengan peningkatan pengetahuan perawat mengenai kegawatan kardiovaskuler. Harapan kedepannya secara tidak langsung kegiatan pengabdian kepada masyarakat ini akan 
meningkatkan kualitas pelayanan perawat Rumah Sakit Universitas Sebelas Maret. Saran pengabdian kepada masyarakat ke depan adalah dengan pengabdian dengan pelatihan jantung dasar secara praktek langsung bagi perawat di Rumah Sakit Universitas Sebelas Maret.

\section{UCAPAN TERIMA KASIH}

Ucapan terima kasih dan apresiasi diberikan kepada LPPM UNS yang telah memberi dukungan moral dan dana terhadap program pengabdian masyarakat ini melalui hibag grup pengabdian dana APBN Universitas Sebelas Maret tahun 2021. Selanjutnya, ucapan terima kasih dan apresiasi juga diberikan kepada PPNI Rumah Sakit Universitas Sebelas Maret yang telah bersedia untuk bekerja sama dalam kegiatan Pengabdian Kepada Masyarakat berupa Pelatihan Elektrokardiografi bagi perawat.

\section{DAFTAR PUSTAKA}

1. World Health Organization. Cardiovascular Diseases. 2017. http://who.int/mediacentre/factsheets/fs317/en/

2. Twistiandayani R., Niluh K. Hubungan Perilaku Perawat Dalam Menginterpretasi EKG Dengan Penanganan Aritmia. Journals Of NersCommunity, Volume 3, No 2. 2012.

3. Kalangi CS., Edmond LJ., Victor FF. Gambaran Aritmia pada Pasien Penyakit Jantung Koroner di RSUP Prof. Dr. R. D. Kondou Manado. Jurnal e-Clinic, Volume 4, Nomor 2. 2016.

4. Pusat Data dan Informasi Kementrian Kesehatan RI, 2013. Situasi Kesehatan Jantung. http://infodatin-jantung.pdf, 26 Desember 2017Marlisa

5. Ignativius \& Workman. Medical surgical nursing. Patient centeredcollaborative care. Philadephia: Saunders ;2010..

6. Eri Yanuar. A \& Happy Indah.K. Keperawatan Kritis. Jakarta:AndiHarminati;2011.

7. Rifai A., Dwi S. Peningkatan Kemampuan Interpretasi Electrokardiogram (ECG) Perawat Dengan Pembelajaran Pelatihan dan Multimedia di RSUD Dr. Soeratno Sragen.Jurnal Terpadu Ilmu Kesehatan,Vol. 6, No. 1. 2016. 